\title{
Youth Sport Coaching and the Importance of Maintaining Participation: Why Evidence Must Underpin Notions of Performance, Talent, and Development
}

\author{
Philippe Crisp* \\ Institute of Sport, University of Chichester, UK
}

\begin{abstract}
There are numerous benefits attached to the idea of lifelong physical activity. Because of this, various governmental and sports organisations seek to promote positive behaviours and potential health aspirations through the use of sport. This critical commentary seeks to highlight some of the issues that surround this topic, most notably the lack of suitable training or understanding for many of the practitioners who deliver youth sport (coaches and teachers). The implications for incorrect or limited understanding within the context of youth sport practice sessions are numerous, particularly when the ideas of performance, competition, and talent are used but not necessarily understood, with increased drop-out rates perhaps of most significance. The contention of this commentary is that those delivering youth sport must develop an appreciation of evidence-based practice that, fundamentally, places the developmental needs of youth at its heart, prioritises participation, and sees the use of competition as a means to an end, not the end itself.
\end{abstract}

\section{Keywords}

Youth sport, Excellence, Relative age effect, Potential, Physical literacy, Attrition

In recent times, the importance of youth sport has been given increasing prominence through the way in which many governments worldwide promote sport and physical activity (PA) through both school and community sectors. Much of the rationale underpinning the manner in which policy discussions on sport and youth sport are influenced is based on the belief that it has a number of, inarguable, positive properties. This is in the way it is seen to act as a suitable vehicle and activity through which positive development can be facilitated. This contribution to youth development, characterised by the way sport is seen to help foster and facilitate attributes such as resilience, decision making, and personal accountability, is complimented by the very real acknowledgement that young people need to develop lifelong participation in sport and PA to help prevent certain common health problems and chronic diseases. Moreover, with the populations of many western societies experiencing increased levels of stress, PA, again, is proven to be a helpful panacea [1,2].

Of course, there are a number of areas of concern here, particularly when we consider that the people who most often articulate and socialise young people into the habit of participating in sport and PA are sports coaches and sport and physical education (PE) teachers. Perhaps most notably, there is a seemingly difficult navigation between how sports coaches and sport and PE teachers can alternate, or perhaps reconcile, any differences between the terms and practice of performance and development. This is particularly so when we consider the aforementioned benefits of youth sport and what might be considered to be the most important element of encouraging sport for this age group, that to keep and promote healthy nations and populaces, young people need to develop lifelong sporting or PA habits.

Whilst no singular, authoritative definition of either performance or development within the context of sport can be given (particularly when the terms are culturally and historically located), broadly, many authors are consistent in the way that they can be conceptualised $[3,4]$. The first, performance, relates more to the areas of high level sport, high level competency and execution of skill, and is oftentimes situated within the domains of representative or professional level sport [5]. The second, development, is a more arbitrary term that oftentimes within the context of sport signifies

*Corresponding author: Philippe Crisp, Programme leader for Sport Development and Coaching, Institute of Sport, University of Chichester, UK

Accepted: July 04, 2019

Published online: July 06, 2019

Citation: Crisp P (2019) Youth Sport Coaching and the Importance of Maintaining Participation: Why Evidence Must Underpin Notions of Performance, Talent, and Development. Arch Sports Med 3(2):162-165 
Citation: Crisp P (2019) Youth Sport Coaching and the Importance of Maintaining Participation: Why Evidence Must Underpin Notions of Performance, Talent, and Development. Arch Sports Med 3(2):162-165

how individuals, teams, or organisations can develop their basic skills, abilities, and execution [6,7]. However, the term is also used to describe the intentional use of sport to develop other, non-sport skills, and refers to how sport can be promoted within the context of community $[8,9]$. Fundamentally though, both ways of explaining development necessitate that participants adhere to programmes or timescales of involvement in order to effect any changes. This is in contrast to the nature of performance, which requires categorisations of excellence, and the subsequent eliminations of those not considered capable of operating at what are considered to be appropriate standards.

However, even if we promote coaching philosophies that incorporate a more humanistic, inclusive, and holistic approach to fostering excellence (performance) whilst still ensuring development, there are a range of areas that sports coaches and sport and PE teachers should know and understand in terms of the development of young people. These include the relationship between growth, maturation, and chronological age, and the impacts that this has on the identification of talent, the grouping and classification of players, and the participants' subsequent engagement with sport or PA.

In truth, asking sports coaches and sport and PE teachers to understand many of the determinants of physical growth may prove problematic, particularly given the training and education pathways that many follow in order to work in these professions. To be clear, for sports coaches this can be a series of short qualifications (sometimes gained in as brief a time as two days), and for the sport and PE teachers, there will be a range of other disciplines they will need to cover in order to become education professionals, so they will not necessarily be sport 'experts' across a range of key physiological, biomechanical, and psychological areas. Admittedly, at a basic level of understanding, the evidence that differences in the rate of growth between young participants has a major influence on inter-individual variations in performance in young athletes (with early maturing players often outshining late maturing players) is probably without question [10]. Yet further understanding of the determinants of physical growth requires knowledge of complex hormonal relationships that are based upon individual genetic programming, for instance, in terms of growth hormone releasing hormone and somatostatin [11]. Whilst sports coaches and sport and PE teachers do not necessarily need to fully know how the endocrine system works and the full mechanics of growth, some knowledge related to Peak Height Velocity (PHV), such as how this period of fastest upward growth in adolescents impacts upon specific biological indices that improve sporting performance, would be very helpful [12].

Clearly then, the fact that biological processes do not always coincide with chronological age presents significant difficulties for sports coaches and sport and PE teachers. This is in terms of their knowledge base and subsequent understanding of variations in maturity, the differentiation of players, PHV and the subsequent slowdown in growth, and how to structure programming and developmentally appropriate activities. Often, sports coaches and sport and PE teachers without full knowledge and understanding of these areas 'band' players due to chronological age, not biological, which unsurprisingly confers physiological and cognitive advantages to those that are 'older' $[13,14]$. In short, this chronological banding invariably accords an upper hand for those further along in their physical development. To be sure, despite evidence demonstrating that agility and motor skills can be slightly affected at the onset of PHV [15], the post PHV results of increased speed, strength, and size of young people (longitudinal studies indicate that PHV overlaps with the peak weight velocity) invariably results in wide variations of physical capability [16].

The effects of this have been quite pronounced worldwide, and can be illustrated through the many professional sport systems that rely (or have relied) on selecting players based on 'ability' and 'skill' levels at pre-mature stages that are underlined by physical development. Here, there are statistically significant variations between those born in first quartiles of selection years compared to the last quartiles. Put simply, the 'older' the players within a selection year, the higher the chance they have of being selected $[17,18]$, a phenomenon termed the Relative Age Effect (RAE). Overall then, in the sports coaching and teaching fields there is a lack of knowledge related to developmental training needs and, notably, the psychological impact of promoting competition above development. This is particularly evident when the anomaly of RAE is taken into account.

Given the uncertainty of how children and adolescents are trainable pre, circa-and post-puberty, with some studies showing the benefits of strength and high-intensity training for young people [19], and some calling for neuromuscular training models for children and adolescents [20], it is of no surprise that the British Association of Sport and Exercise Sciences (BASES) leads a call for an enlarged evidence base [21]. This is to ensure that we understand the extent to which young people can be 'trained' before any maturational threshold is reached. Currently, the evidence does, in fact, point towards the reality that children and adolescents can be trained pre-puberty. An example of this can be seen in the position statement of the Faculty of Sport and Exercise Medicine UK [22], which summarises their belief that resistance training is helpful for children. As a guide for navigating the various areas of physical performance that can be developed for young athletes, one way in which any 'sensitive' periods of trainability may be able to be seen is through using the onset of PHV as a general principle.

Thankfully, it is helpful that a range of developmental models exists to support us here, both in terms of knowing 'why' young people differ in their development, and how they can be 'trained'. Long Term Athlete Development (LTAD), and the Youth Participation Development Model (YPDM), for instance, refer to adolescent periods of adaptation $[23,24]$. These include fundamental movement skills (that form a foundation for later sports performance), sport-specific skills, and variations in the focus of training programmes within certain training periods that are linked to PHV. Ultimately, both approaches take a periodised, scientific approach to developing athletes that are based upon empirical knowledge. 
Citation: Crisp P (2019) Youth Sport Coaching and the Importance of Maintaining Participation: Why Evidence Must Underpin Notions of Performance, Talent, and Development. Arch Sports Med 3(2):162-165

Crucially, they also both emphasise the development of sport skills above the use of competition itself. Competition is a means to an end then, not the end in and of itself.

Similarly, Côté, et al.'s work [25] on sampling promotes play as the foundation of sport specific skills and also, like the LTAD and YPDM models, outlines the importance of playing multiple sports at a young age. The key difference here though is that sampling considers psychological development as the most important thing to understand, and looks to leave specialisation and intensive training as late as possible. This is in order to ensure that participants continually engage with sport or PA, and do not 'burn-out' and give up sport or PA completely. Indeed, Côté and Hancock [26] further build upon this by impressing the importance of the 3Ps: Performance, participation and personal development, for youth sports within their Developmental Model of Sport Participation (DMSP). Here, they further outline a series of recommendations for programme design that emphasised variety, discouraged over-competitiveness, avoided early specialisation, and focused on fun and practice activities. In sum then, there are models that quite concisely put forward 'good' practice for sports coaches and sport and PE teachers that are based upon empirical knowledge.

Of most note, these models provide guidance that specifically focuses on the development of participants, and emphasises the processes of training and competing, well above any considerations of winning. This is particularly germane to the position that this commentary puts forward, that if the full benefits of participation in sport are to be met (those related to the physical and mental health realms), then keeping young people active in sport and avoiding attrition is paramount.

The position this commentary puts forward then is that increasing the knowledge of sports coaches and sport and PE teachers, within the quite explicit parameters that the paper has outlined (maturation and the necessity of maintaining participation for both performance and development related goals), is paramount. This knowledge can help sports coaches and sport and PE teachers develop their critical consciousness and awareness of the perennial problems that underpin youth sport. To reiterate, these problems fundamentally centre on the distinctions between performance and development and the fact that many coaches, teachers, and indeed some sport organisations perpetuate a focus on providing competitive environments and success above individual player motivation and subsequent retention. The issue remains, however, of how to educate sports coaches and sport and PE teachers with the fundamental building blocks of knowledge to understand performance and development in young people. These are, respectively, the manner in which youth sport coaches and teachers need to understand the differences between both performance and development. And, perhaps most importantly, how they can keep their participants interested in sport and PA.

In sum, burn-out and attrition are of no help to either performance goals or the development of players (in terms of shrinking player pools and potentially missing out on late developers), or just in keeping more participants active for longer periods of time, and thus hopefully entering into more lifelong PA habits. This commentary then asks for a change in the philosophy and nature of much sports coaching and teaching. This change is one that is grounded in theoretically informed explanations, and asks for sports coaches and sport and PE teachers to engage with their participants in a more critically aware fashion, one that prioritises physical literacy, developmentally appropriate activities, and an engagement with sport that makes sure that the role of competition is understood in the context of positive youth sport experiences.

\section{References}

1. Janssen I, LeBlanc AG (2010) Systematic review of the health benefits of physical activity and fitness in school-aged children and youth. Int J Behav Nutr Phys Act 7: 40.

2. Gates AB, Kerry R, Moffatt F, et al. (2017) Movement for movement: Exercise as everybody's business? British Journal of Sports Medicine 51: 767-768.

3. Cross N, Lyle J (2003) The coaching process. ButterworthHeinemann, Edinburgh.

4. Navin A (2011) Sports coaching, a reference guide for students, coaches, and competitors. The Crowood Press, Marlborough.

5. Green M, Houlihan B (2005) Elite sport development: Policy learning and political priorities. Taylor and Francis Group, Routledge, London.

6. Martens R (2004) Successful Coaching. Human Kinetics, Leeds.

7. McMorris T, Hale T (2006) Coaching science: Theory into practice. Chichester, John Wiley and Sons.

8. Holt NL (2009) Positive youth development through sport. Routledge, London.

9. Coalter $F$ (2013) Sport for development: What game are we playing? Abingdon: Routledge.

10. Unnithan V, White J, Georgiou A, et al. (2012) Talent identification in youth soccer. J Sports Sci 30: 1719-1726.

11. Armstrong N (2007) Paediatric exercise physiology. Churchill Livingstone, China.

12. Simpkin AJ, Sayers A, Gilthorpe MS, et al. (2017) Modelling height in adolescence: A comparison of methods for estimating the age at peak height velocity. Ann Hum Biol 44: 715-722.

13. Gall FL, Carling C, Williams M, et al. (2010) Anthropometric and fitness characteristics of international, professional and amateur male graduate soccer players from an elite youth academy. J Sci Med Sport 13: 90-95.

14. Mann DL, van Ginneken PJ (2017) Age-ordered shirt numbering reduces the selection bias associated with the relative age effect. J Sports Sci 35: 784-790.

15. Sheehan DP, Lienhard K (2018) Gross motor competence and peak height velocity in 10- to 14-year-old canadian youth: A longitudinal study. Measurement in Physical Education \& Exercise Science 23: 89-98.

16. Hobold E, Flores LF, Brandt R, et al. (2017) Peak height velocity in anthropometry and body composition of students. Brazilian Journal of Kineanthropometry \& Human Performance 19: 309-315.

17. Mujika I, Vaeyens R, Matthys SPJ, et al. (2009) The relative age effect in a professional football club setting. J Sports Sci 27: 1153-1158. 
Citation: Crisp P (2019) Youth Sport Coaching and the Importance of Maintaining Participation: Why Evidence Must Underpin Notions of Performance, Talent, and Development. Arch Sports Med 3(2):162-165

18. Kearney $P$ (2018) The influence of nationality and playing position on relative age effects in rugby union: A cross-cultural comparison. South African Journal of Sports Medicine 29: 1-4.

19. Ferrete C, Requena B, Suarez-Arrones L, et al. (2014) Effect of strength and high-intensity training on jumping, sprinting, and intermittent endurance performance in prepubertal soccer players. J Strength Cond Res 28: 413-422.

20. Myer GD, Lloyd RS, Brent JL, et al. (2013) How young is "Too Young" to start training? ACSMs Health Fit J 17: 14-23.

21. McNarry M, Barker A, Lloyd RS, et al. (2014) The BASES expert statement on trainability during childhood and adolescence. The Sport and Exercise Scientist 41: 22-23.
22. (2015) Youth resistance training. Faculty of sport and exercise medicine UK.

23. Balyi I, Way R, Higgs C (2013) Long-term athlete development. Champaign IL: Human Kinetics.

24. Lloyd R, Oliver J (2012) The youth physical development model. Strength and Conditioning Journal 34: 61-72.

25. Côté J, Horton S, MacDonald D, et al. (2009) The benefits of sampling sport during childhood. Physical and Higher Education Journal 74: 6-11.

26. Côte J, Hancock DJ (2016) Evidence-based policies for youth sport programmes. International Journal of Sport Policy and Politics 8: 51-65. 